\begin{tabular}{llll}
\hline$\Omega$ & $\square$ & Q \\
M.L. Gupta' & 'Dept of Chest and TB, SMS & Sector 1/635, New & drmlgupta@sify.com \\
J. Sinha & Medical College & Vidhyadhar Nagar Jaipur, & \\
C. Bhandari' & 'Dept of Radiodiagnosis, & Jaipur, Rajasthan 302O23, \\
S. Singh' & Getwell Polyclinic Clinic, & India & \\
& Jaipur, India & & \\
& & \\
& &
\end{tabular}

\title{
Emphysema and bronchiectasis in a 48-year-old male
}

\section{Case report}

A 48-yr-old male was admitted to the hospital with a complaint of chronic cough with mucoid expectoration for the past 27 years. His symptoms frequently worsened in the form of fever, increase in the amount of expectoration and foul smell of expectoration. The patient also complained of difficulty in coughing up sputum. Cough had been associated with exertional dyspnoea for the previous $10 \mathrm{yrs}$. There was no history of haemoptysis, wheezing, allergic reactions, weight loss or chest pain.

The patient had been on bronchodilators and antibiotics intermittently with partial relief in symptoms during this period. There was no significant family history of similar or other illnesses.

On general physical examination, grade-I clubbing was present. On auscultation, the patient had bilateral coarse crepitations over the chest. When the patient was asked to cough, it was weak/ineffective and there was a loud, rasping sound. Routine blood counts, biochemistry and serum $\alpha_{1}$-antitrypsin levels $\left(1.58 \mathrm{~g} \cdot \mathrm{L}^{-1}\right)$ were within normal limits. Frontal view chest radiograph and high-resolution computed tomography (CT) of the thorax were performed (figs 1 and 2).

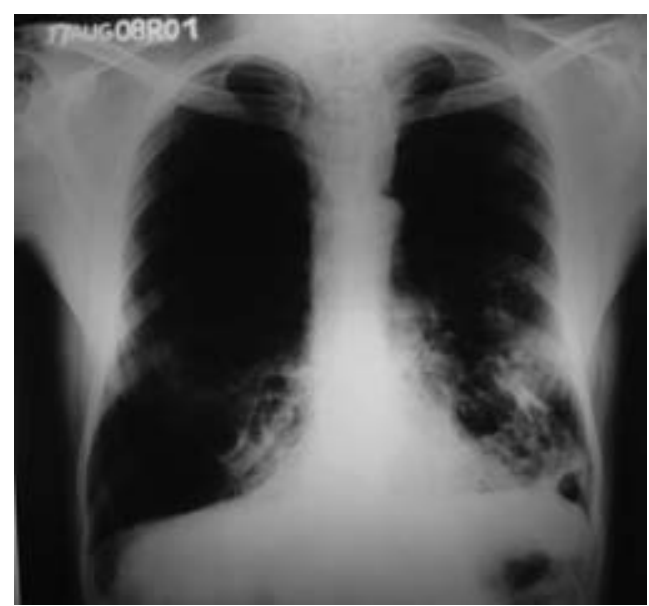

Figure 1

Chest radiograph.

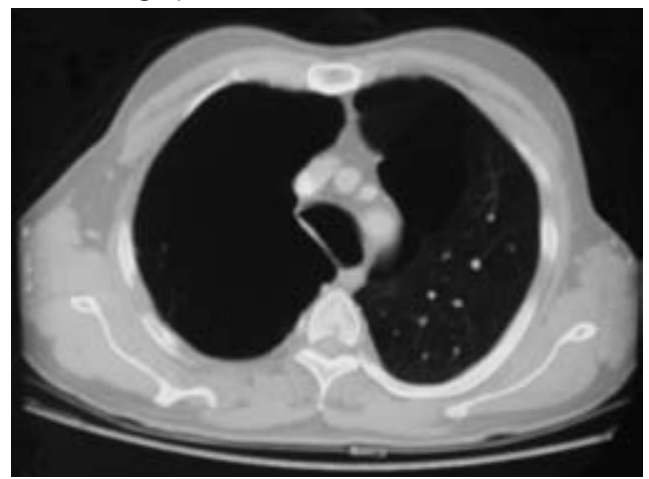

Figure 2

High-resolution CT.

\section{Task 1}

Interpret the chest radiograph and $\mathrm{CT}$ images.
Statement of interest None declared. 


\section{Answer 1}

Chest radiography (fig. 1) suggests extensive emphysema in both lungs and cystic changes suggestive of bronchiectasis in the left lung. The CT scan section (fig. 2), above the aortic arch, shows an enlarged and irregularly shaped trachea.

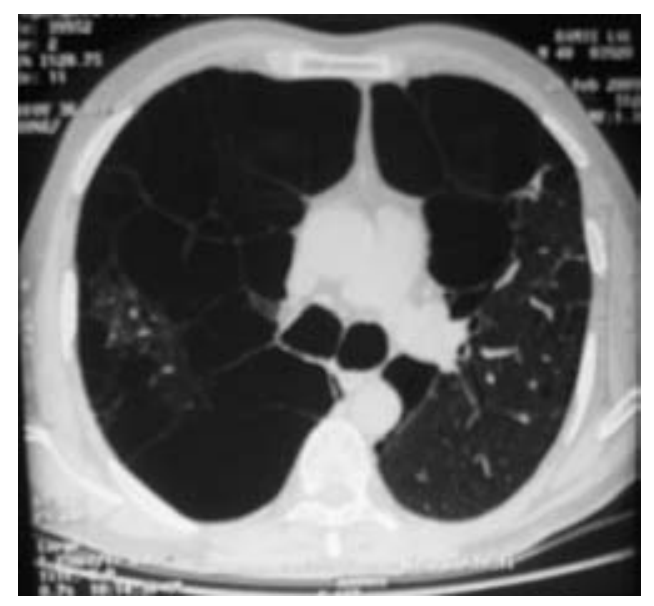

Figure 3

High-resolution CT just below the carina.

A high-resolution CT section (fig. 3) just below the carina showed marked centrilobular and panacinar emphysema in both lungs. A cystic form of bronchiectasis was also seen in places. Both main bronchi appear dilated.

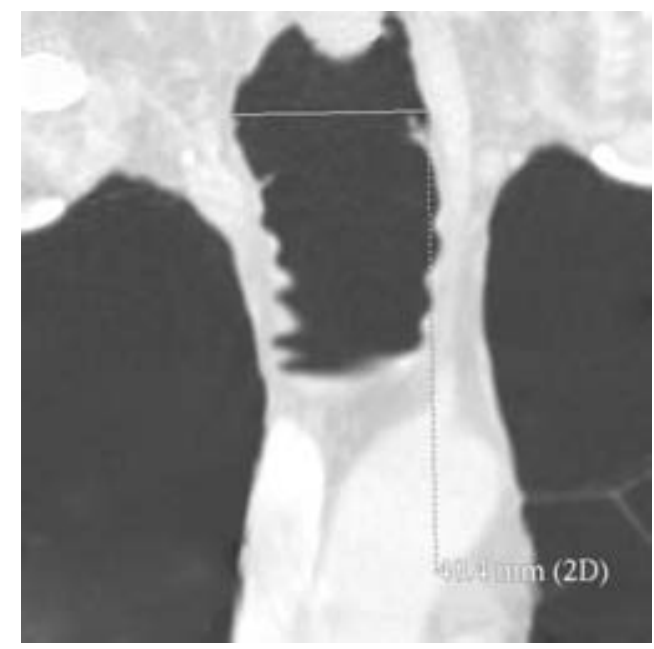

Figure 4

Coronal image of thoracic CT.

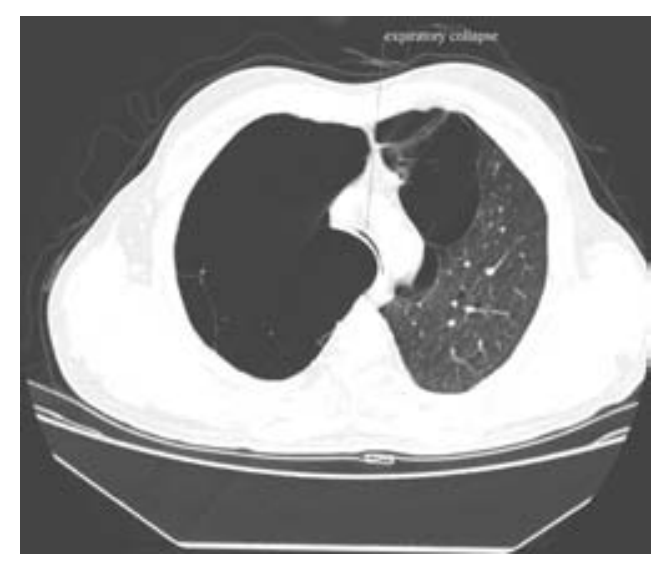

Figure 5

Expiratory CT.

\section{Task 2}

1) How would you describe the coronal image of thoracic CT (fig. 4)?

2) What does the expiratory $C T$ image suggest (fig. 5)?

3) Suggest a possible diagnosis for this patient. 


\section{Answer 2}

1) The coronal reconstruction image of thoracic CT shows an undulating/ scalloping appearance of the inner wall of trachea, suggestive of tracheal diverticulosis.

2) The complete collapse of the trachea on expiratory $\mathrm{CT}$ indicates tracheal flaccidity and tracheomalacia.

3) The strong possibility of tracheo bronchomegaly (Mounier-Kuhn syndrome) should be considered in this patient. However, it would be neces sary to know the exact diameter of the trachea and/or bronchi at a certain specified level.

A thoracic CT section in the axial plane, $2 \mathrm{~cm}$ above the aortic arch, showed a tracheal diameter of $42.6 \mathrm{~mm}$ (fig. 6). These findings are consistent with the diagnosis of tracheobronchomegaly.

On fibreoptic bronchoscopy, an enlarged trachea was seen. Other findings during bronchoscopy were prominence of cartilaginous rings and a diverticulum in the left subglottic region (fig. 7). There was a marked diminution of tracheal diameter during expiration. These findings further support the diagnosis of tracheobronchomegaly in this patient.

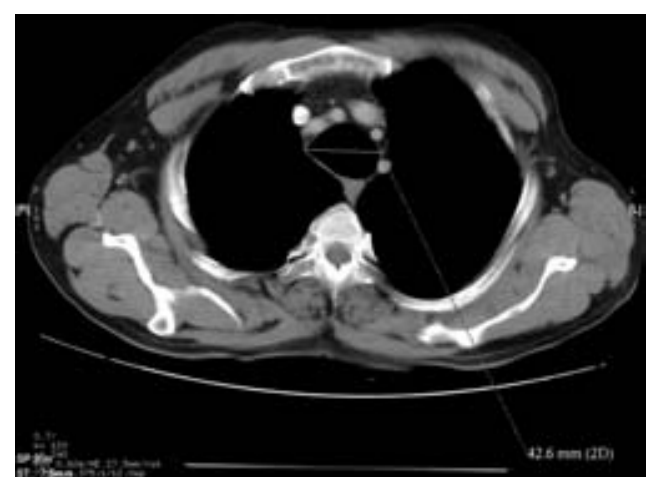

Figure 6

Thoracia CT section in the axial plane.

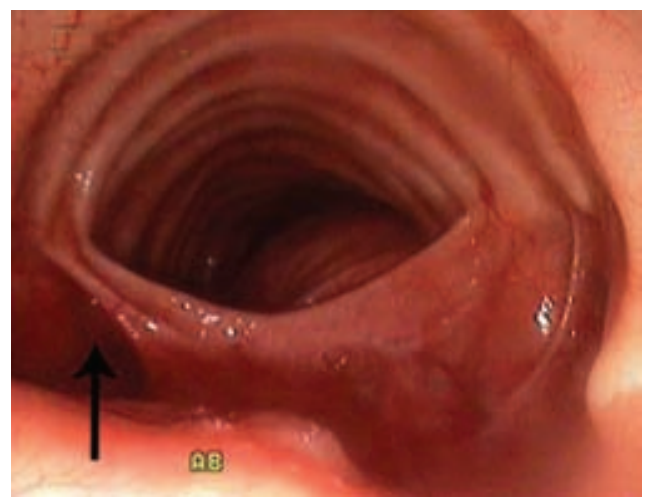

\section{Figure 7}

Cartilaginous and a diverticulum (arrow) in the left subglottic region.

\section{Task 3}

How would you manage this patient? 


\section{Answer 3}

The patient should be referred to a longterm physical therapy treatment programme. Infective exacerbations will need frequent courses of antibiotics. The diffuse nature of the pathology precludes any form of surgical treatment. However, the use of tracheobronchial prostheses in advanced cases has been reported [1].

\section{Discussion}

The aetiology of this rare syndrome is not clearly understood, although associations with cutis laxa in children [2], Ehlers-Danlos syndrome in adults [3], occurrence in two siblings [4] and absence of tracheobronchial muscle fibres and myenteric plexus [5] suggest that a developmental or congenital connective tissue defect is responsible for this disease. However, presentation of tracheobronchomegaly in the third or fourth decade of life and the absence of a connective tissue disorder in most cases favour an acquired cause. SHIN et al. [6] have suggested that chronic irritants, such as cigarette smoke or environmental pollution, might play an important role in the pathogenesis of this disease.

The diagnosis of tracheobronchomegaly can be made on routine chest radiography, bronchography, chest CT and magnetic resonance imaging. For an adult, any diameter of the trachea, right main bronchus and left main bronchus that exceeds 3.0, 2.4 and $2.3 \mathrm{~cm}$, respectively, on a standard chest radiograph is diagnostic of tracheobronchomegaly [7]. On chest CT, tracheal diameter of
$>3 \mathrm{~cm}$ measured $2 \mathrm{~cm}$ above the aortic arch, a diameter of right and left main bronchus of $>2.0 \mathrm{~cm}$ and $>1.8 \mathrm{~cm}$, respectively, are considered diagnostic features of this syndrome [8]. Other causes of tracheal widening, e.g. cutis laxa and Ehlers-Danlos syndrome [9], were not considered in the present case.

Tracheal diverticulosis is another important feature of tracheobronchomegaly, and is seen in about one-third of patients. Atrophied elastic and muscular tissues between two cartilages tend to bulge in the form of diverticulosis, resulting in a scalloping appearance of the air column of the tracheal tree.

Among the lung parenchyma changes, a combination of bronchiectasis and emphysema is unique to this syndrome. This happens because of the abnormal flaccidity of the trachea, which predisposes to ineffective cough and retained secretions, resulting in bronchiectasis. Expiratory collapse of the tracheobronchial tree causes emphysema in these patients. Only a few other conditions have concomitant emphysema and bronchiectasis. These include $\alpha_{1}$-antitrypsin deficiency [10] and, rarely, anorexia nervosa [11]. Both of these could safely be excluded in this case.

The present case not only met all the radiological criteria required for the diagnosis of this syndrome, but also exhibited all possible bronchoscopic findings in such a case. To conclude, Mounier-Kuhn syndrome should be suspected in any patient with chronic productive cough with underlying emphysema and bronchiectasis. Careful attention to central airways, in such settings, is obligatory to discover this uncommon disorder.
The authors would like to thank M. Gupta for his secretarial help.

\section{References}

1. Barakat ], Belleguic C, Le Garff G, et al. [Treatment of tracheobronchomegaly with Ultraflex prosthesis. A case report.] Rev Pneumol Clin 2002; 58: 19-22.

2. Wanderer AA, Ellis EF, Goltz RW, et al. Tracheobronchomegaly and cutis laxa in a child: physiologic and immunologic studies. Pediatrics 1969; 44: 709-715.

3. Aaby GV, Blake HA. Tracheobronchomegaly. Ann Thorac Surg 1966; 2: 64-70.

4. Johnston RF, Green RA. Tracheobronchomegaly: Report of five cases and demonstration of familial occurrence. Am Rev Respir Dis 1965; 91: 35-50.

5. Nadich DP, Webb WR, Muller NL, et al. Computed Tomography and Magnetic Resonance of the Thorax, 3rd Edn., Philadelphia: Lippincott-Raven, 1999; 161-290.
6. Shin MS, Jackson RM, Ho KJ. Tracheobronchomegaly (Mounier-Kuhn syndrome): CT diagnosis. Am J Roentgenol 1988; 150: 777-779.

7. Himalstein MR, Gallagher JC. Tracheobronchomegaly. Ann Otol Rhinol Laryngol 1973; 82: 223-227.

8. Blake MA, Chaoui AS, Barish MA. Thoracic case of the day: Mounier-Kuhn syndrome (tracheobronchomegaly). Am J Roentgenol 1999; 173: 824-825.

9. Choplin RH, Wehunt WD, Theros EG. Diffuse lesions of the trachea. Semin Roentgenol 1983; 18: 38-50.

10. Jones DK, Godden D, Cavanagh P. $\alpha-1$ Antitrypsin deficiency presenting as bronchiectasis. BrJ Dis Chest 1985; 79: 301-304.

11. Cook VJ, Coxson HO, Mason AG, et al. Bullae, bronchiectasis and nutritional emphysema in severe anorexia nervosa. Can Respir J 2001; 8: 361-365. 